\title{
Discourse Analysis of the Victory Speech of President Trump from the Perspective of Theme and Thematic Progression Patterns
}

\author{
Xiulian Liu ${ }^{1}$ and Huijun Zhang ${ }^{2}$ \\ School of Foreign Languages, Jianghan University, Wuhan 430056, China \\ ${ }^{1}$ liuxiulian1000@sina.com, ${ }^{2} 1014851138 @ q q . c o m$
} Keywords: Theme and thematic progression patterns; Discourse analysis; Victory speech of
American president Trump

\begin{abstract}
The victory speech of presidential election in the United States is given by the new president after a long and tough election journey. It will not only reveal the identity of the new president but also conclude the summary of the election, the joy of the result and new political views. As a president with unique individual characteristics and lots of controversies, the victory speech of president Trump should be focused. Theme and thematic progression patterns are mainly used to analyze the meaning and structure of discourses. By this method, the content and structure of Trump's victory speech can be better understood. Appropriated theme and thematic progression patterns will be helpful to convey the information. Parallel and concentrated progression patterns are used to emphasize some important information. Continuous and crossed progression patterns are helpful for the development of the speech.
\end{abstract}

\section{Introduction}

After nearly two years' presidential election, Donald Trump, an American businessman, has won the final victory of this tough journey. As an entrepreneur with few experiences on politics, this result has shocked not only the United States but also the whole world. From the time that Trump announced to run in this election, he has got a lot of attention from the world out of his individual characteristics. His views on politics, his family and his personal speeches have all been hot issues to politicians, scholars, businessmen and ordinary people. Up to now, a lot of researches related to Trump have been done and the topics conclude various areas, such as Trumpism, national relationship after Trump taking power, Trump's political speeches and so on[1]. As a brilliant person, Trump does well in business. At the same time, he is also a good writer. Though there are some daring words and sentences in Trumps' speech, the structures and contents of his speeches are designed quite tactfully from the perspective of theme and thematic progression patterns.

\section{Theory of Theme and Thematic Progression Patterns}

Theme and thematic progression patterns belong to the functional linguistics. "The concepts of theme and rheme are first put forward by the founder of the Prague School-Mathesius"[2]. In this theory, a sentence or a clause is made up by theme and rheme. Theme is the starting point of a clause. Rheme is the other part of a clause except theme. Theme is the foundation of a clause and it tells readers what the information begins with. 'Usually, theme is the 'Given Information'. It is the information that readers are familiar with and rheme is the 'New Information' where the topic expands"[3]. So rheme is the kernel part of the new information. According to the book $A n$ Introduction to Functional Grammar written by English famous linguist Halliday[1], "theme and rheme can be classified as simple theme, multiple theme and clausal theme"[4] . "Simple theme concludes only what Halliday calls "conceptual element". Usually, simple theme is made up by noun phrase, adverbial phrase or prepositional phrase"[4]. For example:

"(1) The man in the wilderness(T) said to me. (R)

(2) Slowly and quietly(T) he pushed the door open. (R)

(3) For want of a nail(T) the shoe was lost. (R)"'[5] 
The above three clauses' themes are noun phrase, adverbial phrase and prepositional phrase respectively. Multiple theme concludes more than conceptual element, it may also conclude textual element or interpersonal element. Sometimes these three elements appear together in one multiple theme. It is sure that whatever theme it is, it always concludes conceptual element. "Clause theme" can be each kind of theme which has been inferred above. Theme and rheme only analyze the clause level. "However, in the former clause and the following one, there are always some connections between their themes and rhemes. This is also the way that information flows in a certain text. This is called thematic progression"[6]. Thematic progression is the way to find out how clauses connected with each other. So it analyzes the textual level. "Danes proposes the concept of thematic progression first. He claims that the organization of information in texts is determined by 'the choice and order of utterance themes' "[7]. With the further research of thematic progression by lots of linguistics, now there are lots of patterns of thematic progression. According to Halliday's theory, there are four basic patterns of thematic progression[2] . They are parallel progression, concentrated progression, continuous progression and crossed progression. Parallel progression refers to several clauses with the same theme and different rhemes. Concentrated progression refers to several clauses own the same rheme and different themes. In continuous progression, the rheme of the former clause is the theme of the next clause. In crossed progression, the themes and rhemes of the former clause and the next clause are crossed or partly crossed. That is to say "T2=R1" or "R2=T1", which means the theme of the second clause equals to the rheme of the former one and the rheme of the second clause equals to the theme of the former clause. Now, theme and thematic progression are highly used when analyzing the structure and meaning of texts.

\section{Discourse Analysis of Trump's Victory Speech from the Perspective of Theme and Thematic Progression Patterns}

Trump's victory speech was given as soon as the news that Trump has got more votes than Hillary. As the first time to make a speech with the identity of the new American president, this speech conveys a lot of new information. By analyzing it through theme and thematic progression patterns, the meaning and structure of it can be better understood.

Concrete Analysis of the Meaning and Structure of Trump's Victory Speech. The following is the concrete analysis of this victory speech. For convenience, "T" stands for theme and " $\mathrm{R}$ " stands for rheme in the following analysis.

In the first two paragraphs of Trump's speech, as the winner of the big election, Trump expressed his respected feeling to the other candidate-that is Hillary • Clinton. "I (T1) 've just received a call from Secretary Clinton (R1). She (T2) congratulated us (R2). It(T3)'s about us (R3). On our victory, and I (T4) congratulated her and her family on a very, very hard-fought campaign (R4). I (T5) mean she fought very hard (R5). Hillary (T6) has worked very long and very hard over a long period of time (R6), and we (T7) owe her a major debt of gratitude for her service to our country (R7). "[8] In these seven clauses, it is clear all the themes are simple themes and unmarked themes. In this way, the beginning words or phrases of each clause are also the subject of it. So it is very clear for readers to know that what the topic is talking about. In this text, T2=R1, they are both "Hillary". We can know these two clauses are concerned about Hillary at an instant. Then R2=R3= "us", connected with R1-"Hillary". It is obvious that the information is about "Hillary and us". At the following, T4=T5= "I", R5=T6=R7 = "Hillary", this makes the information flow to "I and Hillary". From the analysis of theme and rheme, the information flows from "Hillary and us" to "I and Hillary". First, Trump tells his audiences that Hillary has congratulated his party and his supporters for their victory of this election. Next, theme changes to "I", Trump has expressed his respect to Hillary of the election. Finally, at the last theme, Trump uses "we" to show the unity between him and the country. These seven clauses contain all the four patterns of thematic progression. The parallel progression used is typically "I". By using it, it emphasizes "Trump", the winner of the election, really respects the great competitor-Hillary. The concentrated progression here emphasizes that this victory is our victory. This cheerful result belongs to everyone who has supported Trump. 
The continuous progression pushes the information to flow naturally. The crossed progression makes the context more connected. By the flows of the information of this victory speech, Trump first shows Hillary's congratulation to people. Then he expresses his respect to Hillary. At the beginning of the speech, it shows a good relationship between him and Hillary after the election. Though they are competitors to each other, they still respect each other. It also shows the generosity of a new president of the "United States. "Now it (T1) is...nation (R1) I (T2) say...united people (R2).It (T3) is time (R3). I (T4) pledge...Americans (R4), and this (T5) is so important to me (R5). For...past (T6), of which...country (R6). As I've...beginning (T7), ours...heir family (R7). It (T8) is...it will (R8)" [7]. In this part, the first clause is a multiple theme and it concludes conceptual element and textual element. "Now" is a textual element, it is used here to emphasize the time. It is the time that Trump has become the new president of the United States. For the former five clauses, $\mathrm{T} 1=\mathrm{R} 2=\mathrm{T} 3=$ "it", $\mathrm{T} 4=\mathrm{R} 5=$ "I". The information is about the time "now" and "I". R1=R2= "together", while announcing his new identity to the world, Trump also pays attention to the problem of unity. During the election, the America is in a situation of pision. Now, as the election ended, Trump has become the president. The first problem that he needs to solve is the pision. $\mathrm{R} 7=\mathrm{T} 8=$ "campaign" and $\mathrm{R} 7=\mathrm{R} 8=$ "great movement", these two sentences are crossed thematic progression, which better explains that it is not a bad election but a great one with the wish to make America better and brighter. These two sentences aim to solve the pision problem. Trump expresses that the election has a common aim that is to get together and build America together.

The next part of the speech talks about what Trump and all American will do after Trump being the president. The changes of themes are "I-that-tremendous potential-I-tremendous potential-it-every single American". From the theme, it is clear that the topics of this part are about "Trump", "potential" and "American". The rhemes of these clauses are "potential-I-country-beautiful thing-potential". From this we can see that the new information is also the thing mainly connected "potentials". By comparing and connecting the theme and rheme, it is clear that Trump wants to develop the great potential of America with all Americans together. It is also another perspective of unity. From this part, Trump has expressed his political spirit that is to construct America with everyone together. The themes of this part are all simple themes and unmarked themes. By this way, Trump expresses his political wishes directly. At the same time, this direct way also adds the determination of the speaker. Here, it shows Trump's determination and confidence to make America better as his election slogan-"Make America Great Again". "We (T1) are going to fix our inner cities and rebuild our highways, bridges, tunnels, airports, schools, hospitals (R1). We(T2)'re going to rebuild our infrastructure, which will become, by the way, second to none (R2), and we (T3) will put millions of our people to work as we rebuild it (R3)"[8]. This paragraph includes three clauses and the thematic progression patterns are quite obvious. It is a typical concentrated progression. These three clauses have the same theme "we" and different rhemes. These three "we" used here are also the subjects of the three clauses, so it is easy to know it talks about "we" and emphasizes it a lot. Actually R2 is almost equal to R1. They are both "going to do something connected the infrastructure". R2 is the further compliment of R1. However, R3 is different. R3 is "put people to work". From the theme and thematic progression, it is easy to divide the structure of this part. The former two clauses talk about "what is going to do" and the third one is "how to do". These three sentences are short and clear. However, it does great work here. Trump uses these three sentences to tell Americans that he concerns a lot about American infrastructure and the jobs of Americans. These two topics are thought highly of by Americans at this time. So in such a situation, at the victory speech, to express such political points is definitely accepted by all Americans.

Next part of the victory speech is also about the political plans. The themes of this part are "we-I-we-it-we-we-we-we-we-no-nothing". Only seeing from theme, it seems that it is a great parallel progression with the common theme "we" and "no". However, to see from rhemes, something different can be found. The rhemes are "national growth and renewal-leverage talents-happen-economic plan-strongest economy-too big-beyond reach". From rhemes, it is not difficult to find that in rhemes, "economic plan" equals "strongest economy" and "too big" equals 
"beyond reach". From this, it can be found theme and thematic patterns is not fixed and solo, two clauses may include more than just one thematic pattern. In this kind of sentences, the inner structure is tighter. From the theme, these clauses are started with the topic "we". "We" refers to both Trump and all the other Americans. It still emphasizes the unity of a country. All Americans will get together and do something. Then looking at the new information, it focuses on growth and economy of America. Connected the "Given and New Information" together, it is easy to know what this part is talking about, which is "we get together to use our talents to do contributions to American economy and growth". The last two themes and rhemes are different from the other. However, they are the same with each other. So when theme and rheme are all the same, the meaning of the two clauses should be the same, too. Actually, they are the same, it is used here for emphasizing.

After the democratic political plan, Trump's speech briefly turns to the cross-national political plan. "I (T1) want to tell the world community that while we will always put America's interests first, we will deal fairly with everyone, with everyone (R1), all people and all other nations. We (T2) will seek common ground, not hostility, partnership, not conflict (R2)"[8]. This cross-national politics is actually short, just two sentences, but it goes well. R1=R2= "deal fairly", T1= "I" and $\mathrm{T} 2=$ "we", so it is a concentrated progression. The new information is to keep good relationship with everyone, every country. America will hurt nobody while finding ways to grow itself. The themes are different. As these two clauses are unmarked clauses, the subjects are different. One subject is "I" and the other subject is "we". From these two themes, Trump announces to the world that as a new president of America, he will not do the things that will hurt other countries and all Americans will do the same things as he. Looking for peace is always the foreign political method of America.

The following half part of the victory speech is concerned about Trump's thanks to those people who have done great jobs to this joyful result. This part makes up the majority of the speech. First, Trump expresses thanks to his family. The themes of this part are "first I"-“I"-“They"-“They"-"I"-“and my brother Robert-and also my late brother Fred"-"to Melania and Don and Ivanka and Eric and Tiffany and Barron". Most of the themes are still simple themes, in the middle there is a multiple theme which includes a structural element "and". This is to transfer the theme from "they" to "my brother". If only analyzing from the themes, the information can be got that this part is talked about "I" and "my family". The audiences can easily learn that Trump is going to say something about him and his family. So the rhemes following each sentence is going to tell the new information of the topic -"Trump and his family". The rhemes corresponded with these themes are "thank to my parents"-"learned so much from them"-"were wonderful"-"great parents"-"thank my sister"-"are great"-"I love you and I thank you". The information flows of the rhemes turning thanks to parents, brothers and sisters. Except the last sentence, the former several clauses are unmarked clauses. The subjects of these sentences are put at the beginning to make audiences clearly know what it is talking about. Meanwhile, in this way, the structure of the text is clear. Trump expresses his thanks to his parents, brothers and sisters respectively. However, the last sentence is a marked one. The theme of this clause is "to Melania and Don and Ivanka and Eric and Tiffany and Barron". This is not a subject, it is an object. In this sentence, Trump put the object first. In the one hand, he emphasizes who he expresses his thanks for. These people are different from parents and siblings. These people are his children and wife who provide strong support to him during the tough election. On the other hand, Trump has not expressed thanks one by one like the other family members. It also shows a unity of his big family here. The changes of theme patterns also change the structure of his context. It can also improve audience's attraction to the speech. The thematic progression pattern of these clauses is mainly continuous progression. In this way, the "given information" and the new information connects tightly and flows slowly. At the following speech, the thanks of Trump come to his great group.

"What a great group (T1), you've all given me such incredible support (R1), and I (T2) will tell you that we have a large group of people (R2). You (T3) know, they kept saying we have a small staff (R3). Not (T4) so small (R4). Look (T5) at all of the people that we have (R5). Look (T6) at all 
of these people (R6). And Kellyanne and Chris and Rudy and Steve and David(T7), we have got tremendously talented people up here, and I want to tell you it's been very, very special (R7).'[8] $\mathrm{T} 1=\mathrm{R} 2=$ "great group", this is a crossed progression, the given information of the first sentence is the same with the new information. So these two sentences are telling the great group of the election. It shows that it is because of the great election group that Trump can finally won the election and become the president. R3= R4="small group", and T4 ="not", these two clauses are concentrated progression. However, the theme "not" and the two "small group" exactly expresses that the campaign group of Trump is not a small group. These two sentences are connected by the same rheme, which makes the structure tighter and more logical. In the following speech, Trump has expressed his thanks to the former mayor-Rudy Giuliani, Governor Christie and several other people who have done great jobs in this tough election. Simple theme and continuous progression are highly used here. Simple theme is to make the structure of clauses brief and clear and continuous progression is used to make a tight logic between the clauses. "We (T1) will do a great job (R1). We (T2) will do a great job (R2). I (T3) look very much forward to being your president (R3) and hopefully at the end of two years or three years or four years or maybe even eight years you (T4) will say so many of you worked so hard for us (R4)" [8]. In this case, T1=T2 and R1=R2, so the given information and new information of the two sentences are totally the same. Here is Trump's wish about his term of office. He wishes him and Americans will do great jobs at his term. The following information is "I"-"your president"-"you"-"work hard for us". This information has explained the relationship of "I", "you", and "us". That is "I am you president and let us get together to work hard for ourselves." At last, Trump has made a conclusion of the election and the new hope for the future of America in his term. "And I (T1) can only say that while the campaign is over (R1), our work on this movement (T2) is now really just beginning (R2). We (T3)'re going to get to work immediately for the American people (R3) and we(T4)'re going to be doing a job that hopefully you will be so proud of your president (R4). You (T5) will be so proud (R5)"'(Trump, 2016). $\mathrm{R} 1=\mathrm{T} 2=$ "campaign", it is a continuous progression. It transfers the election campaign to the campaign to rebuild America naturally. T3=T4="we", at the beginning, it tells people the following information is about "we". R3 and R4 are different but they are something that "we" will do in the following days, to make a brighter America. It also shows Trump's responsibility. As a president, "I"-Trump, will not let you down.

By analyzing the victory speech of Donald Trump, it can be found that the flow of information is clear which also makes the understanding of the text easier and better. Through analyzing the theme and thematic progression patterns, the victory of Trump's speech contains respects of Hillary, unity of America after the election, political views of President Trump home and abroad, thanks to people who have done great jobs in the campaign, president's promises and good wishes for the term. The four thematic progression patterns not only emphasize and make information more complete, but also make the structures of sentences various, which can avoid bored feelings from audiences.

Effects of the Theme and Thematic Progression Patterns Used in Trump's Victory Speech. As a speech that made in a cheerful and noisy atmosphere, Trump used a lot of simple and unmarked theme in his speech, which made the audiences get what he was going to talk about quickly. In this way, the meaning of the speech can be easily followed by people in that circumstance. At the same time, some typical themes are highly used in Trump's victory speech, like "we" and "I", which mainly emphasize the unity of him and all Americans and his own political ideas. It also makes the relationship between the speaker and audiences closer. In order to emphasize, Trump has also chosen some marked themes, which makes the audiences pay attention to some special information. The thematic progression patterns used in this speech are flexible. Four thematic progression patterns appear in the speech and their frequencies vary not too much, which can make the structure of the speech more flexible and increase the interest of the audiences. Among the four thematic progression patterns, continuous pattern is used most. This makes the clauses in the speech more connected and information flows more naturally and logically. Audiences can also understand the speech better by this means. The second frequent thematic progression pattern is the parallel progression. By using it, the speaker can emphasize some typical 
themes and make the speech understood more easily by the audiences.

\section{Conclusion}

Most of the theme in Trump's victory speech is simple and unmarked one. In this way, the audiences can catch the subject at the beginning of a clause, which make the understanding of the contents of this speech easier. At the same time, the speaker uses this way to express his thought directly. In Trump's victory speech, he uses "we" and "I" as the theme for many times. As a winner of this election, Trump uses "we" as a theme to emphasize that he and all Americans is a group and they will rebuild America together. The frequent theme "we" has shown Trump's attitude towards all Americans. As a new president, he has emphasized the importance of unity. Another frequent theme - "I" emphasizes two things. On the one hand, Trump has shown others that his new identity. On the other hand, Trump has expressed his promises and wishes to his new political career. As an audience of such speech, by analyzing the speech from theme and thematic progression patterns, the meaning and the structure of it can be better understood. As a speaker of a speech, the simple and unmarked theme should be used in speech fluently. It can help audiences to grasp the key point quickly. At a noisy atmosphere, it can also help the speaker to express the main idea forcefully. In order to make the speech more various and interesting, several kinds of thematic progression patterns should be used in the speech. Meanwhile, the highly uses of crossed progression and concentrated progression can help the development of the speech and the flow of the information.

\section{References}

[1] L. Y. Zhang. "Critical Discourse Analysis of Trump's Inaugural Address," The Fortune Times 8(2017):157.

[2] M.A.K. Halliday. Introduction to Functional Grammar. Beijing: Foreign Language and Research Press, 2000.

[3] Q. Xu \&H. Y. Guo . "The Analysis of Thematic Progression Patterns of English Advertisement." Overseas English. 14(2014) P: 285-287.

[4] H. P. Liang. "Introduction to Theme Structure and Thematic Progression Patterns." Journal of Jiangxi Normal University 3(2018): P68-72. (In Chinese)

[5] Z. L.Hu, Y. S. Zhu, D. L. Zhang \& Z. Z.Li. Introduction to Systemic Functional Linguistics. Beijing: Peking University Press, 2005. (In Chinese)

[6] P. A. Leong . "Topical Themes and Thematic Progression: the "Picture" of Research Articles." Text\&Talk 35.3(2015): P289-315.

[7] Q. Zhou. "The Study of Thematic Progression Patterns in TEM8 News Discourse." Overseas English. 15(2017): P40-41. (In Chinese)

[8] Donald, Trump. Victory Speech of American Election. 2016 